\title{
A wider role for general dental practice?
}

\author{
James W. Aukett ${ }^{1}$
}

\section{Key point}

FDI World Dental Federation has recognised the wider role played by dentists in the COVID-19 pandemic.
Dentists' training places them in a good position to take a wider role in overall health promotion.
UK government's intention to re-model healthcare services towards a prevention-based system opens the door for GDPs to take a wider role.

\begin{abstract}
The role of general dental practice within the NHS is limited to the direct practice of dentistry. Pandemic situations have identified the capability of dentists to take a wider role in patient care, which has been recognised by the FDI World Dental Federation. With the UK government's intention to re-structure primary healthcare to recognise lifestyle elements as the important feature of a new prevention emphasis, could and should the unique position of general dental practice play an important and integral role in promoting overall health and wellbeing?
\end{abstract}

\section{Introduction}

The recent publication by the FDI World Dental Federation of their Delivering optimal oral health for all ${ }^{1}$ acknowledges contributions of dentists to national efforts to treat and manage the COVID-19 pandemic worldwide. The potential for dentists, with their medical training and clinical experience, to be actively involved in wider health issues and wider healthcare is outlined. The suggestion that dentists have the knowledge and skills to be redeployed within the healthcare system in times of crisis is developed to argue that they could be usefully enlisted at all times to raise patients' awareness of general health issues, specifically in the areas of sedentary lifestyles, obesity and tobacco cessation. Reinforcing primary prevention and encouraging patients to take responsibility for their own health would synergise with other activities by health departments.

Coincidentally, an announcement from the UK government reported a change of direction for the NHS, ${ }^{2}$ allegedly initiated by the COVID19 crisis and its effects. Even though smoking rates have declined, conditions linked to poor diet and sedentary lifestyles are increasing, including obesity, diabetes and dementia. To

${ }^{1} 16$ South Way, Seaford, East Sussex, BN25 4JG, UK. Correspondence to: James W. Aukett

Email address: j.aukett@sky.com

Accepted 6 April 2021

https://doi.org/10.1038/s41415-021-3475-0 address this increasing burden on the NHS, a focus on lifestyles, healthy behaviours and prevention is planned to become a prominent feature of care provided. In addition, the removal of barriers to integration and cooperation in achieving better health for the population is emphasised. This move is perhaps well overdue, having been recommended by the World Health Organisation (WHO) in the Ottawa Charter ${ }^{3}$ in 1986. The Charter advises all governments to address five main areas of promoting health. The first four relate to public policymaking, creating supportive environments, strengthening communities and developing personal skills. The fifth advises re-orienting health services, in particular using a holistic definition of health which recognises that health is multideterminant dependent.

Putting the two together, is there an opportunity for dentists to widen their role? This would be in accord with the aims of the newly structured health service and would recognise the place of the dental profession firmly within, and an integral part of, the medical profession.

Worldwide, morbidity and mortality have moved from infectious diseases to noncommunicable, chronic diseases of lifestyle. In two major papers, just after the turn of the century, the $\mathrm{WHO}^{4,5}$ noted that four of the most prominent chronic diseases - cardiovascular diseases, cancer, chronic obstructive pulmonary disease and type II diabetes - are linked by common and preventable biological risk factors, notably high blood pressure, high blood cholesterol (and glucose) and being overweight, and by related major behavioural risk factors identified as unhealthy diet (including alcohol use), physical inactivity and tobacco use. As a consequence, it is advised that action to prevent these major chronic diseases should focus on controlling these key risk factors in a well-integrated manner, and that they could be significantly reduced by addressing certain behaviours of youth and adolescence. It was clearly apparent to the dental profession that all major oral and dental diseases - dental caries, periodontal disease, oral cancers, erosion and accidental injury - are related to the same risk factors, including an unhealthy diet, tobacco use, alcohol use, stress and lifestyle (including hygiene and accidents). ${ }^{6}$ The same message was relayed in a WHO global strategy on diet, physical activity and health ${ }^{7}$ in 2017.

There are perhaps three areas to explore.

\section{Are dentists sufficiently knowledgeable?}

Some of the areas suggested are already within the remit of the dental profession. A conscientious dentist advising on reduction in sugar intake in the diet should be aware of the danger of suggesting alternatives which may be high in salt and/or fats, and that it is not possible to alter just one aspect of a diet. Any dietary advice, or analysis of a dietary record, should already include considerations of fibre, salt, fats and sugar, areas within which a dentist should 
be knowledgeable and competent. A dentist will have an awareness of the effects of sugar, directly and indirectly, on obesity, cardiovascular disease, skin conditions, liver disease, type II diabetes and obesity, which makes a discussion with the patient more holistically-based and more likely to elicit a reaction. Familiarity with Delivering better oral health $(D B O H)^{8}$ and the "Eatwell guide" provides good background knowledge.

The dental profession is acutely aware of the significance of tobacco and alcohol on periodontal disease and oral cancers, and should routinely be addressing these issues in accordance with $\mathrm{DBOH}$ and NICE guidelines. Dental team members are well positioned to revise their awareness of the wider systemic and psychological effects of these substances.

\section{The established link between oral and systemic health and disease}

Oral health and systemic heath are inextricably linked. Many definitions of oral health include references to it as a fundamental component of health, and its role in contributing to and being reliant upon general health, both physically and psychologically (for example, FDI World Dental Federation).${ }^{10}$ There are many references to the link between oral disease and systemic disease ${ }^{11,12}$ between oral and pulmonary diseases, ${ }^{13}$ and a growing body of evidence to suggest an association or a link between oral (periodontal) diseases and cardiac health. ${ }^{11}$ Presence of similar bacteria and antigens gives this link credibility. ${ }^{14}$

A link between obesity and caries has been observed, ${ }^{15}$ and an association between obesity and periodontal disease has been suggested. ${ }^{16}$

Dentists have a considerable role to play in a patient's overall health and wellbeing - and perhaps not just a role, but an obligation.

\section{Ethical considerations}

Is there an ethical basis for dentists to take a wider view of their patients' health? Arguments have raged over the years as to the ethics of suggesting lifestyle changes to patients because many clinicians may not have the in-depth understanding of the psycho-social environment of the patient and will therefore be meddling in areas they do not understand. ${ }^{17}$

But this is countered by arguments that it is incumbent on people working in the health field to recommend lifestyle changes, and that it is irresponsible and unethical not to do so. ${ }^{18}$

We are all familiar with the question as to whether omitting to do something which would bring good is equally as bad as doing something which will do harm. Acts of omission may be considered as unethical as any non-beneficial or maleficent act. In other words, not giving beneficial advice is as bad as if dentists were giving bad advice.

The Nuffield Council on Bioethics ${ }^{19}$ concludes that the state has a duty to help everyone to lead a healthy life and that other parties have an obligation to promote health. Those who sell ill health do so without moral or ethical consideration, often using strong advertising and emotive methods in the mass media. This is alien to our professional ethics of defending the autonomy of the patient. Dentists, by advocating alternative behaviour, would be restoring the balance with harmful influences, thereby helping to maintain personal autonomy. Freedom and the right to free choice is not only maintained but strengthened by giving the patient enhanced capability and opportunity to weigh up alternatives in the context of their lives.

\section{Conclusion}

Is the timely issue of these two publications an indicator that the dental profession should establish an extended role within the wider boundaries of the medical profession, and possibly within the remit of an evolved prevention-led NHS? The characteristics, understanding and treatment of dental and oral disease have change dramatically over the past decades. Changes in the epidemiology of dental disease and in the understanding of the lifestyle-dominant-based determinants have already led to changes in the characteristics of dental practice, with some dentists recognising this and attempting to change accordingly and others resisting the necessary change. Patients are now more demanding and their needs and expectations of their dental team extend beyond a drill and fill paradigm of care. Consecutive governments and varying commissioning bodies have spouted the rhetoric of change, but in dentistry, remuneration and governance systems fail to support or encourage practitioners to adopt a change from restorative practice.

Depending on where you look, reports show that between $45 \%$ and $80 \%$ of adults, and a higher proportion of children, visit a dentist within a two-year period. The dental profession is in a strong position to contribute to the health of the nation. A coincident opportunity like this to raise the profile of the profession may not arise again in the immediate future. Is this an opportunity to explore, or a route to be avoided?
Ethics declaration

The author declares no conflict of interest.

\section{References}

1. FDI World Dental Federation. Delivering Optimal Oral Health for All. 2021. Available at https://www. fdiworlddental.org/sites/default/files/2021-02/Vision2030-Delivering\%200ptimal-Oral-Health-for-All_0.pdf (accessed February 2021).

2. Department of Health and Social Care. Working together to improve health and social care for all: White paper setting out legislative proposals for a Health and Care Bill. 2021. Available online at https://www.gov.uk/ government/publications/working-together-to-improvehealth-and-social-care-for-all (accessed February 2021).

3. World Health Organisation. Milestones in Health Promotion: Statements from Global Conferences. 2009. Available at https://www.who.int/healthpromotion/ Milestones_Health_Promotion_05022010.pdf (accessed February 2021).

4. World Health Organisation. Global strategy for the prevention and control of noncommunicable disease. 2002. Available at https://www.afro.who.int/sites/ default/files/2017-06/NCD-Global_Strategy_for_the Prevention_and_Control_of_NCD_2000.pdf (accessed February 2021).

5. World Health Organisation. The World Health Report 2002 Reducing Risks, Promoting Healthy Life. 2002. Available at https://apps.who.int/iris/bitstream/handle/10665/42510/ WHR_2002.pdf (accessed February 2021).

6. Sheiham A, Watt R G. The common risk factor approach: a rational basis for promoting oral health. Community Dent Oral Epidemiol 2000; 28: 399-406.

7. World Health Organisation. Global Strategy on diet, physical activity and health. 2017. Available at https:// www.who.int/dietphysicalactivity/strategy/eb11344/ strategy_english_web.pdf (accessed February 2021).

8. Public Health England and Department of Health Delivering better oral health: an evidence-based toolkit for prevention. 2017. Available at https://assets. publishing.service.gov.uk/government/uploads/system/ uploads/attachment_data/file/605266/Delivering better_oral_health.pdf (accessed February 2021).

9. Public Health England. The Eatwell Guide: Helping you eat a healthy, balanced diet. 2016. Available at https:// assets.publishing.service.gov.uk/government/uploads/ system/uploads/attachment_data/file/742750/Eatwell Guide_booklet_2018v4.pdf (accessed February 2021).

10. Glick M, Williams D M, Kleinman D V etal. A new definition for oral health developed by the FDI World Dental Federation opens the door to a universal definition of oral health. Br Dent J 2016; 221: 792-793.

11. Dietrich T, Webb I, Stenhouse L et al. Evidence summary: the relationship between oral and cardiovascular disease BrDent J 2017; 222: 381-385.

12. Sharma P, Busby M, Chapple L, Matthews R, Chapple I. The relationship between general health and lifestyle factors and oral health outcomes. Br Dent J 2016; 221: 65-69.

13. Manger D, Walshaw R, Fitzgerald R et al. Evidence summary: the relationship between oral and pulmonary disease. BrDent J 2017; 222: 527-532.

14. Gutmann J L. Focal infection revisited - the swinging of the pendulum. Dent Historian 2017; 62: 81-90.

15. Dye B A, Mitnik G L, lafolla T J, Vargas C M. Trends in dental caries in children and adolescents according to poverty status in the United states from 1999 through 2004 and 2011 through 2014. J Am Debt Assoc 2017; 148: 550-565.

16. Saloom H F, Papageorgia S N, Carpenter M T, Cobourne M T. Impact of obesity on orthodontic tooth movement in adolescents. J Dent Res 2017; 96: 547-554.

17. Veatch $R$ M. Ethical aspects of recommending lifestyle interventions to patients. JAMA 2003; 290: 2660; author reply 2660-2661.

18. Anderson J W. Reply to: Ethical Aspects of Recommending Lifestyle Interventions to Patients. JAMA 2003; 290: 2660-2661

19. Nuffield Council on Bioethics. Public health: ethical issues - a guide to the report. 2007. Available at http:// nuffieldbioethics.org/wp-content/uploads/2014/07/ Public-Health-short-guide.pdf (accessed February 2021). 